\title{
Galvanic Esophageal Injury
}

\section{Chandrasekar Thoguluva Seshadri, Raja Yogesh Kalamegam, Viveksandeep Thoguluva Chandrasekar ${ }^{1}$, Gokul Bollu Janakan}

\author{
Department of Gastroenterology, Medindia Institute of Medical Specialties, Chennai, Tamil Nadu, India, ${ }^{1}$ Department of Internal Medicine, \\ SUNY Upstate Medical University, Syracuse, New York, USA
}

\begin{abstract}
\end{abstract}
\section{Introduction}

Accidental foreign body ingestion is a common clinical problem encountered in pediatric practice. Although most foreign bodies pass off spontaneously through naturalis, without any adverse outcomes, a few warrant urgent endoscopic intervention. The necessity for endoscopic retrieval depends on the physical characteristics of the foreign body which may indicate the likelihood of impaction, and the chemical nature of the foreign body which predicts the possibility of mucosal injury. Here, we report the case of a 3-year-old child who presented with an impacted button battery in the esophagus which necessitated emergency endoscopic retrieval.

\section{Case Report}

A 3-year-old child was brought with the history of throat pain, incessant cry, drooling of saliva, and refusal to feed over the

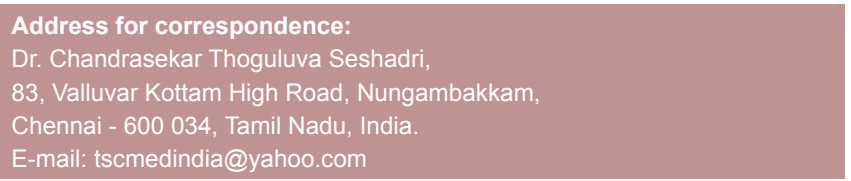

\begin{tabular}{|l|c|}
\hline \multicolumn{2}{|c|}{ Access this article online } \\
Website: & Quick Response Code \\
www.jdeonline.in & \\
\hline & DOI: \\
10.4103/0976-5042.202816 &
\end{tabular}

past $8 \mathrm{~h}$. The local examination of the oral cavity and neck was unremarkable. Accidental foreign body ingestion and esophageal impaction were suspected. X-rays of the neck and chest were taken, which revealed a circular radio-opaque disc with a thin rim of peripheral radiolucency [Figure 1] lodged at the level of the cervical esophagus. The diagnosis of an impacted button battery was thus made based on this characteristic finding at imaging.

On diagnosis, emergent endoscopy was done which revealed a button battery impacted at the level of the cricopharynx. The admission to endoscopy time was approximately $1 \mathrm{~h}$. Extensive edema and ulceration at the site of impaction hindered optimal endoscopic visualization and extraction, necessitating fluoroscopic assistance [Figure 2]. The foreign body, a 3V Lithium-ion battery measuring $2 \mathrm{~cm}$ in diameter [Figure 3], was removed successfully. Postremoval, endoscopy revealed a short segment of ulcerated area covered by black eschar - Zargar Grade 3a [Figure 4], at the site of impaction. Considering the possible sequelae of a stricture, a nasogastric tube was placed. Oral sucralfate at a dose of $1 \mathrm{~g}$ qid was started on the $3^{\text {rd }}$ day onward after the throat pain subsided, and continued for the next 2 weeks. The

This is an open access article distributed under the terms of the Creative Commons Attribution-NonCommercial-ShareAlike 3.0 License, which allows others to remix, tweak, and build upon the work non-commercially, as long as the author is credited and the new creations are licensed under the identical terms.

For reprints contact: reprints@medknow.com

How to cite this article: Seshadri CT, Kalamegam RY, Chandrasekar VT, Janakan GB. Galvanic esophageal injury. J Dig Endosc 2017;8:39-41. 


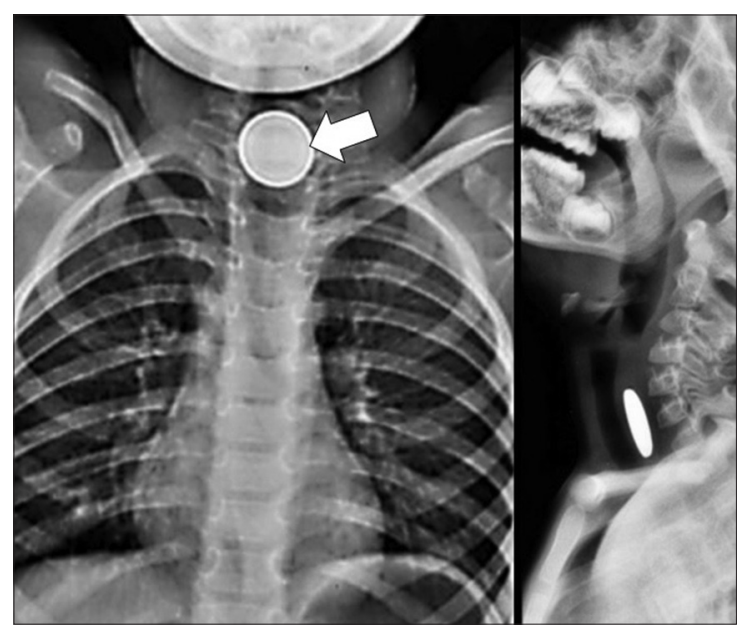

Figure 1: X-ray chest showing radio-opaque disc-shaped shadow with a distinct outer radiolucent rim seen lodged at the level of the cervical esophagus

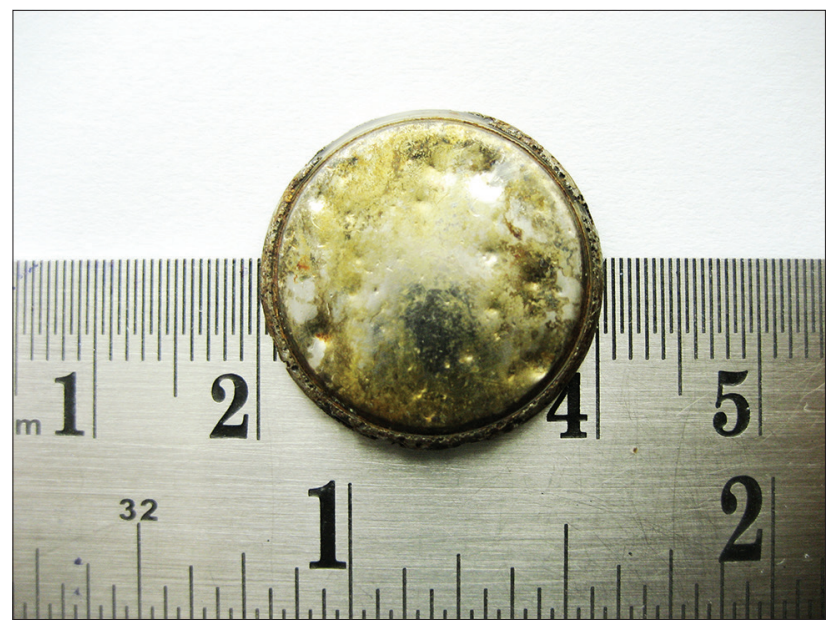

Figure 3: The extracted foreign body: A $2 \mathrm{~cm}$ sized corroded 3V Lithium-ion battery

child recovered without any sequelae. Relook endoscopy done after 6 weeks showed a linear scar surrounded by mild erythema without any stricture at the site of previous impaction [Figure 5].

\section{Discussion}

Foreign body ingestion is a common gastrointestinal emergency in pediatric practice. Toddlers are orally curious and tend to sample objects through the mouth. Not surprisingly, the incidence of foreign body ingestion is highest between the age group of 6 months and 3 years. ${ }^{[1]}$ With the increasing usage of button batteries in toys and household appliances, the incidence of accidental button battery ingestion is on the rise. ${ }^{[2]}$ Esophageal impaction of a button battery differs considerably from that of a similar sized inert object in that, in addition to the mechanical injury by pressure necrosis, injury also occurs as a consequence of alkali leakage,

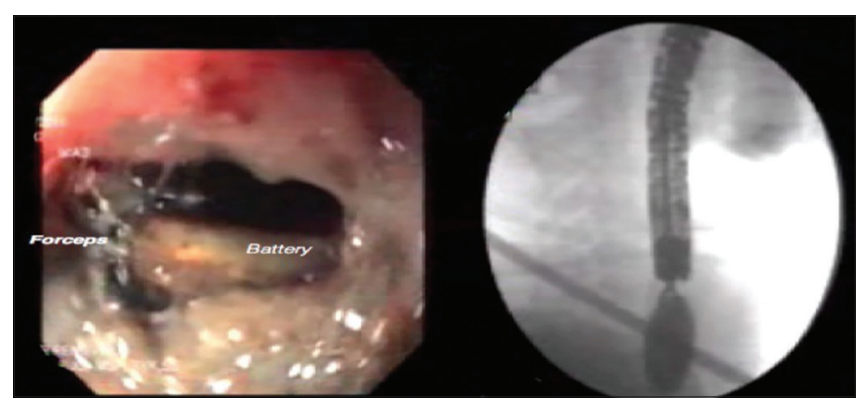

Figure 2: Battery extracted endoscopically using rat-tooth forceps under fluoroscopic guidance

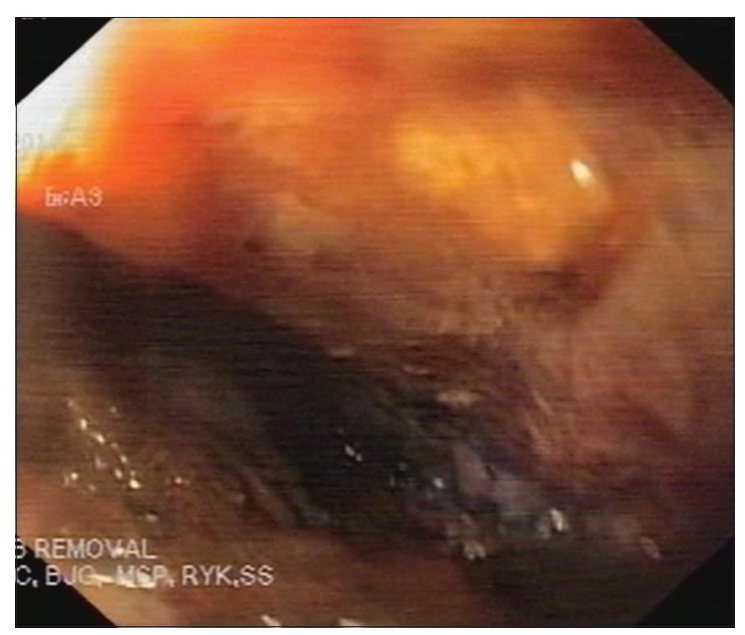

Figure 4: Site of impaction showing focal ulceration with black eschar

electrical injury, and heavy-metal toxicity. ${ }^{[3]}$ The factors influencing outcome, therefore, include the residual electrical charge, chemical composition and diameter of the battery, and most importantly the ingestion-to-intervention time. Button battery impaction is an endoscopic emergency, wherein mucosal injury can occur as early as $1 \mathrm{~h}$ and potentially fatal complications such as esophageal perforation, mediastinitis, tracheoesophageal fistula, esophago-aortic fistula and death, within $4-6 \mathrm{~h}^{[4,5]}$ When history is obscure, as often is the case with children, an $\mathrm{X}$-ray showing a circular radio-opaque disc with an outer rim of radiolucency clinches the diagnosis of an impacted button battery and warrants emergency endoscopic removal.

\section{Learning points}

- Retching and drooling in children should arouse the suspicion of impacted esophageal foreign body

- Esophageal impaction of button battery carries high morbidity and is potentially fatal, mandating emergency endoscopic removal

- Button battery impaction, in addition to pressure necrosis due to its physical dimensions, also causes considerable injury secondary to alkali leakage, electrical injury, and heavy-metal toxicity

- Tell-tale circular radio-opaque shadow with radiolucent 


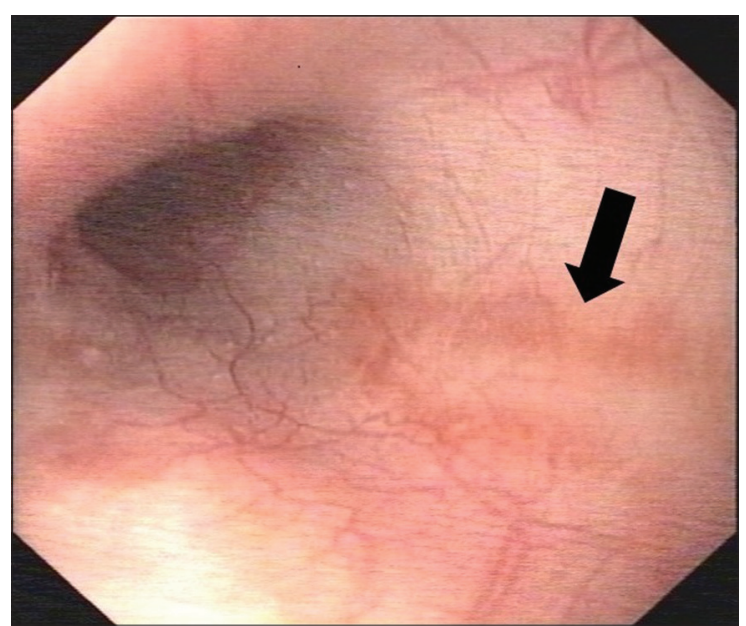

Figure 5: Follow-up endoscopy after 6 weeks showing a faint linear scar with surrounding erythema (arrow) at site of impaction

rim on X-ray clinches the diagnosis of impacted button battery and differentiates it from an impacted coin
- Follow-up is required in view of the risk of delayed sequelae such as stricture.

\section{Financial support and sponsorship}

Nil.

\section{Conflicts of interest}

There are no conflicts of interest.

\section{References}

1. Chen MK, Beierle EA. Gastrointestinal foreign bodies. Pediatr Ann 2001;30:736-42.

2. Litovitz T, Whitaker N, Clark L. Preventing battery ingestions: An analysis of 8648 cases. Pediatrics 2010;125:1178-83.

3. Kost KM, Shapiro RS. Button battery ingestion: A case report and review of the literature. J Otolaryngol 1987;16:252-7.

4. Litovitz T, Schmitz BF. Ingestion of cylindrical and button batteries: An analysis of 2382 cases. Pediatrics 1992;89(4 Pt 2):747-57.

5. Maves MD, Carithers JS, Birck HG. Esophageal burns secondary to disc battery ingestion. Ann Otol Rhinol Laryngol 1984;93(4 Pt 1):364-9. 